tin contains a non-histone protein which has the ability to render the histone genes available for transcription. It is the absence of the protein in $\mathbf{G}_{1}$-phase chromatin rather than the presence of some inhibitor molecule which distinguishes $\mathrm{G}_{1}$-phase from $\mathrm{S}$ phase chromatin. Thus the importance of the non-histone proteins and their interaction with DNA and histones in the control of specific genes is again indicated.

The type of in vitro transcription and reconstitution experiments presented in these papers are beset with difficulties not only in their execution, but also in their interpretation. Often such work meets with much criticism and scepticism because factors such as just how the DNA probe was made and how the reconstitution and hybridisations were performed can alter the results significantly and consequently lead to misinterpretations. Also one can always criticise this type of work by pointing out that the studies are after all in vitro and may have nothing to do with the transcriptional process which occurs in the cell. Certainly this is correct; however, in vitro transcription and reconstitution experiments despite their difficulties are useful in pointing out which components of the in vivo system may be of particular significance. In a system as complex as that for the control of eukaryotic genome expression, such clues to which factors are likely to be most important is certainly useful as a guide for further thought and research.

\section{Higher ozone concentrations over Britain}

\section{from Peter D. Moore}

THE elevated levels of ozone in the atmosphere of London and other parts of Britain have been a source of concern for some years (see Nature, 256, 537 ; 1975). Man-made pollution is undoubtedly a major source of ozone in the troposphere and inflates the 2-4 p.p.hm. which is normally found there. Petrol and diesel engines are considered to be important in this process of ozone generation, for they emit nitric oxide and also uncombusted hydrocarbons which oxidize the nitric oxide to nitrogen dioxide. $\mathrm{NO}_{2}$ is liable to photochemical dissociation in daylight leading to the generation of atomic oxygen which interacts with molecular oxygen to produce ozone, $\mathrm{O}_{3}$.
Ozone is a powerful oxidant and is known to damage both animal and plant tissues (Bell and Cox, Environ. Pollut., 8, 163; 1975). The Environmental Protection Agency of the United States has established an air quality standard of a maximum ozone concentration of 8 p.p.hm. for an hour's duration. In London, the Greater London Council's guideline has been set at the same level.

For some years this guideline has been exceeded, usually during anticyclonic periods in summer. On July 13, 1972, a peak value of 11 p.p.hm. $\mathrm{O}_{3}$ was recorded in Central London (Derwent and Stewart, Nature, 241, $342 ; 1973)$. On page 580 of this issue of Nature Ball presents data for the summer of 1975 in London and registers a peak value of 15 p.p.hm. on June 26, 1975, almost twice the GLC guideline level. This is the kind of concentration at which, according to the WHO and the US Department of Health, a degree of eye irritation and aggravation of respiratory diseases may be expected.

This is still well below the 28 p.p.hm. of Sydney, over 30 p.p.hm. in Tokyo and up to 99 p.p.hm. in Los Angeles. It is, however, a disturbing trend. Ball has kindly provided some preliminary figures for the current (1976) summer in London which suggest that the trend towards higher ozone concentrations in Britain is continuing. Even in early May of this year, levels of 18 p.p.hm. had been recorded in London. Subsequently values up to 21 p.p.hm. have occurred, and the guideline concentration has of ten been exceeded for as many as $40 \mathrm{~h}$ per week over the whole of London. Records from Harwell are even higher than these.

Ball's data do help to resolve the question of whether Britain's ozone is largely derived from the Continent or whether our cities make a significant contribution. Cox et al. (Nature, 255, 118 ; 1975) showed that photochemically generated ozone can be transported distances of the order of $100-1,000 \mathrm{~km}$. Continental ozone can enter the British troposphere in sufficient concentration to raise ambient levels to as much as 15 p.p.hm., as was shown during easterly air movements at a recording station in Suffolk during August 1973. Stewart et al. (also in this issue of Nature, page 582) show that high ozone concentrations occur most often on days when the wind direction is north-east, through to south This lends some support to the contention of Cox et al., but it is also true that when anticyclonic conditions prevail the wind is most often in that quarter. As Stewart shows, ozone is highest when temperature and insolation are high, and these conditions are also associated with anticyclones, Ball now demonstrates that among the London recording stations higher values of ozone are found at those sites which receive air masses from over Greater London, and concludes that homegrown ozone represents a significant contribution to our tropospheric load.

To what extent are these recent high levels of ozone a consequence of the unusually sunny, anticyclonic summers we have experienced of late? Only continued monitoring of gaseous pollution over London can answer this. It is salutary to note that in cities like Sydney, ozone became a problem with startling suddenness. A further, unanswered question is the degree to which ozone interacts with sulphur dioxide, our other main gaseous pollutant, in its harmful effects. Menser and Heggestad (Science, 153, 424; 1966) showed that tobacco plants were severely injured by mixtures of $\mathrm{SO}_{2}$ and $\mathrm{O}_{3}$ in concentrations of 24 p.p.hm. and 3 p.p.hm. respectively, whereas neither of these concentrations produced damage on their own. It is possible that this synergistic effect is general, in which case ozone may be an even more serious pollutant than is currently predicted, especially in cities such as London where $\mathrm{SO}_{2}$ concentrations are still high.

\section{Pleistocene mammals}

\section{from $D . W$. Yalden}

Historically, the evidence provided by fossil mammals played a large part in establishing the glacial theory of Pleistocene geology. The discovery in the 1860 s of fossil lemmings in southern England, in particular, was readily accepted as evidence of former tundra conditions. Though early excavations of caves and river terraces concentrated on large mammals, such as mammoths, or on human remains and artefacts, much information on smaller mammals was obtained; this formed the basis as long ago as 1926 for a large (though uncompleted) monograph by Hinton (Monograph of Voles and Lemmings (Microtinae) Living and Extinct, British Museum, (Natural History), London). While this early work established Quaternary biology as a science, it suffered, as pioneering work inevitably must, from being too early. The fossil mammals were subjected to an extremely typological classification, with names founded on extreme variants, and more normal intermediates left unnamed. The very complex nature of 